\title{
LA ESCALADA DEL CRIMEN \\ EN LA MENTALIDAD DEL SIGLO XVI EN UNA RELACIÓN DE SUCESOS DE 1588
}

La literatura impresa en pliegos sueltos o folhetos de cordel ha tenido una larga trayectoria en diversos países iberoamericanos desde la invención de la imprenta, en el siglo xv, hasta nuestros días -especialmente en países como Brasil. En la España del siglo Xvi, uno de los géneros que más éxito alcanzó desde sus primeros años de andadura fue el de las relaciones de sucesos, destinadas a dar noticia -real o ficticia, pero verosímil- de todo tipo de acontecimientos acaecidos dentro y fuera de la Península ibérica. Los sucesos relacionados con la monarquía -ya fueran nacimientos, bodas o exequias-, así como las guerras, batallas, tratados de paz, etc., conocieron una larga tradición en los pliegos sueltos poéticos, junto con otro tipo de noticias como las de incendios, tormentas, terremotos - es decir, desastres naturales de distinta tipología- o las relaciones de martirios, cautivos, renegados, etc. El objetivo y la finalidad que este tipo de obras persiguen no consiste solamente en informar de unos determinados hechos, sino también de entretener y/o conmover a su público, así como servir de vehículo de determinados intereses ideológicos, relacionados, en la mayor parte de las ocasiones, con la propia propaganda política y religiosa de la época, que llegaba a través de diferentes canales que utilizaban los poderes civil y eclesiástico a todos los súbditos del reino.

Dentro de este género cabe destacar los llamados casos horribles y espantosos, que fueron los que alcanzaron mayor éxito durante siglos, ya que comenzaron a imprimirse y publicarse a mediados del siglo XVI, pero su difusión ha llegado -a través de distintos medios y soportes- hasta nuestros días ${ }^{1}$. Estas relaciones de sucesos tremendistas provocan sobrecogimiento y terror, debido a la crudeza de los hechos que describen y a la carga de angustia y padecimiento que transmiten, mediante la narración de conductas amorales, asesinatos, venganzas, torturas, etc. Además del miedo, e incluso pánico, que

1 María Sánchez Pérez, "La transmisión y difusión de los casos horribles y espantosos desde sus orígenes hasta el siglo xxı" (en prensa). 
debían sentir quienes leyeran o escuchasen estos casos horribles, no cabe duda de que el morbo hacia estos sucesos macabros hizo que las masas se sintieran atraídas por este tipo de textos desde sus inicios.

Quisiera fijar la atención ahora en un caso concreto, en un pliego suelto del siglo Xvi donde se nos cuenta un Caso admirable y espantoso, agora nuevamente sucedido en este año de mil y quinientos y ochenta y siete, que trata cómo un mal hijo fue desobediente a sus padres y de la maldición que su madre le hechó, y cómo se tornó moro. Y el riguroso castigo que Dios hizo sobre él, con otras cosas de grande admiración y exemplo para que los padres castiguen a sus hijos. Compuesto por Benito Carrasco, natural de Fuente Vejuna. Impressa con licencia en casa de Hubert Gotard. Año de $1588^{2}$. No nos detendremos ahora en analizar las diversas secciones que suelen presentar esos títulos o paratextos y que responden a unas pautas muy concretas que se repetirán a lo largo de varias centurias ${ }^{3}$; pero sí señalaremos algunas de sus características materiales y tipobibliográficas: se trata de un pliego suelto poético en formato $4^{\circ}$, formado por cuatro hojas, con letra redonda y texto a dos columnas. Carece de grabado xilográfico -algo que no es habitual en estas piezas-y al final del pliego, en A4v se lee: "Véndense en casa de Pedro Ferrer, librero".

Por lo que se refiere a los datos tipográficos, tal y como se indica en el pliego, la obra fue impresa por Hubert Gotard, probablemente en Barcelona, en 1588. Hijo de padre impresor, sabemos que su actividad se desarrolló en diferentes ciudades y, por los datos que se conocen en la actualidad, es muy probable que en dicha fecha se encontrase asentado en Barcelona ${ }^{4}$. Tenemos noticia de que fueron diez los pliegos sueltos poéticos salidos de su imprenta, un número considerable -teniendo en cuenta los conservados- que hace que podamos considerarlo como uno de los impresores más importantes de estas obras en la segunda mitad del siglo XVI.

El autor de la pieza, Benito Carrasco, es uno de los copleros populares más conocidos del Quinientos y "tiene una amplia bibliografía que se extiende desde los últimos años del siglo xvi... hasta, por lo

${ }^{2}$ Se trata de la entrada 94.5 de la obra de Antonio Rodríguez Moñino, Nuevo diccionario bibliográfico de pliegos sueltos poéticos. Siglo XVI, ed. corr. y actualizada por A. L.-F. Askins y V. Infantes, Castalia-Editora Regional de Extremadura, Madrid, 1997. La pieza original se conserva en la Biblioteca Universitaria de Barcelona, signatura [B-59/3/42-18]. Para la transcripción y edición de los textos hemos seguido las normas que aparecen recogidas en el Proyecto de investigación "Cultura populary cultura impresa: corpus, edición y estudio de la literatura de cordel de los siglos XVI y XVII" [BFF2003-00011]. Guía para los miembros del equipo y colaboradores, SEMYR, Salamanca, 2003, pp. 8-9.

3 Para ello véase PEdro M. CÁTEDra, Invención, difusión y recepción de la literatura popular impresa (siglo XVI), Editora Regional de Extremadura, Mérida, 2002, esp. pp. 225 ss.

${ }^{4}$ Juan Delgado Casado, Diccionario de impresores castellanos (siglos XV-XVIII), Arco-Libros, Madrid, 1996, pp. 292-294. 
menos, 1680 en que se seguían publicando pliegos a su nombre" ${ }^{5}$. Sin embargo, este autor no ha suscitado hasta el momento la atención minuciosa de ningún especialista, ya que solamente tenemos sobre él algunos acercamientos parciales a su obra ${ }^{6}$. Sería muy útil un estudio completo y detallado de los pliegos sueltos conservados de este autor, ya que Benito Carrasco posee un aguda sagacidad para componer obras que conecten con los intereses y gustos de la época y, al mismo tiempo, tiene una clara conciencia artística que se percibe de forma evidente al leer cada uno de sus textos.

En este pliego impreso en 1588, Benito Carrasco narra lo que aconteció a un mal hijo que, pese al amor que siempre le habían profesado sus padres, cae en pecado al atentar contra varios preceptos religiosos, ya que continuamente amenaza a sus progenitores e incurre en todo tipo de blasfemias. Aunque en el título del pliego se indica que la madre maldice al hijo por su mal obrar, en el texto es en realidad el padre quien lo hace. El joven asesina a sus dos progenitores y huye de su ciudad, después se tornará moro, esposará a una mora, etc. Tras una larga serie de atroces delitos cometidos por este hombre bajarán del monte unos monstruos que, convertidos en serpientes, perros, leones, etc., terminarán devorándolo. Este sería el resumen de esta obra, pero vayamos por partes.

El texto consta de 431 versos y está compuesto en las conocidas como quintillas dobles o coplas de ciego $^{7}$, aunque en un momento muy determinado -como veremos más adelante- incluye otras estrofas métricas para dotar de mayor dramatismo a su obra. Como es habitual en este tipo de narraciones, comienza la obra con una estrofa introductoria dedicada a Dios para que ayude al coplero en su tarea de redacción y recitación de los versos:

$$
\begin{aligned}
& \text { Mueva mi lengua el Señor } \\
& \text { Iesús, vivo omnipotente, } \\
& \text { para que con su favor } \\
& \text { un caso admirable cuente, } \\
& \text { de gran exemplo y primor. } \\
& \text { Tené atentos los oídos, } \\
& \text { gente por Dios redemida... } \\
& \text { Començad, pluma veloz, } \\
& \text { a narrar lo succedido, }
\end{aligned}
$$

5 M. Cruz García de Enterría, "Más pliegos poéticos del siglo xvi”, StI, 1982-83, p. 20.

6 Véanse JuAn Carlos IzQuierdo, "Un acercamiento a la obra de Benito Carrasco: autor en pliegos sueltos”, en Siglo de Oro. Actas del IV Congreso de la AISO, 1998, pp. 857-868; y DAvid Ferrer, Ávila y la literatura del Barroco, Gran Duque de Alba, Diputación de Ávila, Ávila, 2004.

7 Véase Nieves BARANDA, "Andanzas y fortuna de una estrofa inexistente: las quintillas dobles o coplas de ciego”, Castilla, 1986, núm. 11, 9-36. 
pues que cierto ha acontecido

este caso cruel, atroz,

según por nueva he sabido

(vv. 1-20).

Se dirige, por tanto, a una congregación de gentes arremolinadas en torno al coplero que escucharían ${ }^{8}$, ansiosos, esta noticia llegada -según señala el propio autor- desde Italia, "Allá dentro, en Lombardía, / sucedió este cuento estraño” (vv. 21-22). Si Pedro M. Cátedra aseguraba que, en muchas ocasiones, un rumor podía ser el punto de partida a la hora de componer este tipo de obras ${ }^{9}$, no cabe duda de que así podía resultar en este caso, ya que, como afirma el autor, "pues que cierto ha acontecido / este caso cruel, atroz, / según por nueva he sabido" (vv. 18-20). Tras situarnos geográficamente el lugar de la acción, en la región de Lombardía (Italia), Benito Carrasco señala que este mal hijo era de padre noble y rico, circunstancia que se repite en otras muchas obras de este tipo y es, sin duda, un elemento más a tener en cuenta a la hora de buscar la ejemplaridad en todas estas composiciones ${ }^{10}$. De ahí también que las autoridades civil y religiosa vieran con buenos ojos la proliferación, difusión y venta de estas obras, pues todas ellas acababan con el castigo de los culpables y de quienes infringían la norma y el control establecido. Es más, como señaló Pedro M. Cátedra, en alguna ocasión los predicadores de la época no dudaron en sustituir un sermón por la lectura en voz alta de alguno de estos casos horribles y espantosos ${ }^{11}$.

Continuando con la narración de nuestra obra, Benito Carrasco incluye un breve retrato moral del protagonista y así se nos dice que el mayor pecado de este personaje era blasfemar: "Su vicio era blasphemar / de Iesuchristo sagrado” (vv. 36-37) ${ }^{12}$. Y si el joven, además,

8 Sobre este aspecto puede consultarse María Sánchez Pérez, "A todos quiero contar / un caso que me ha admirado: la convocación del público en los pliegos sueltos poéticos del siglo xvi", en Pedro M. Cátedra (dir.), La literatura popular impresa en España y en la América Colonial. Formas Ẽ temas, géneros, funciones, difusión, historia y teoría, eds. E. B. Carro Carbajal, L. Mier, L. Puerto Moro y M. Sánchez Pérez, Seminario de Estudios Medievales y Renacentistas-Instituto de Historia del Libro y de la Lectura, Salamanca, 2006, pp. 145-159.

9 Pedro M. Cátedra, Invención, difusión y...

10 Tampoco es infrecuente que el espacio geográfico se sitúe más allá de Castilla; en buena medida porque muchos de estos casos serían inventados por estos copleros populares, de ahí que sea muy difícil poder asegurar hoy que estos hechos sucedieran realmente y que esto, al fin, tampoco importe para acercarnos a analizar esta parcela de la literatura popular.

11 Pedro M. CÁtedra, Invención, difusión y...

12 Sobre el hecho de si nos encontramos ante actantes o personajes estereotipados, véase María SÁnchez Pérez, "La retórica de las relaciones tremendistas del siglo xvi", en Praestans labore Victor. Homenaje al profesor Victor García de la Concha, ed. y coord. J. San José Lera, Universidad, Salamanca, 2005, pp. 217-234. 
tiene la mala costumbre de jugar, cada vez que pierde dinero en una partida las blasfemias y juramentos aumentan. De este modo, la blasfemia y el juego se aúnan para caracterizar la maléfica figura del protagonista. De nuevo, la intencionalidad didáctico-moral de la obra queda patente, ya que las causas de esa actitud de rechazo hacia esos vicios deben buscarse en la sociedad del momento. La finalidad ética que persigue el coplero se sitúa en las directrices marcadas tras el Concilio de Trento, junto con algunos de los principales intereses del humanismo español, ya que son frecuentes los tratados y obras morales que pretendían influir en la reforma de las costumbres. Estas obras del momento, así como los sermones de la época son buen ejemplo de la denuncia de diferentes pecados sociales y, entre ellos, destaca el ataque contra el juego y los jugadores. Como cuadro de costumbres de la vida cotidiana de los Siglos de Oro recuérdense los comentarios de Juan de Zabaleta sobre el tahúr y las casas de juego, y más concretamente lo que se deduce de estas palabras conforme a nuestro texto:

Grande inconveniente es estársele viniendo a la boca al que juega, a cada suerte que pierde, los juramentos y los por vidas. El que en todo un año no jura una vez si no juega, jura cada vez que juega mil veces... Si no se puede avenir con su impaciencia, dice recio dos blasfemias, como en venganza de Dios, que ofenden a Dios gravemente y escandalizan extraordinariamente a quien las oye. El pecado del blasfemo es gravísimo, porque es ofensa que se le hace a Dios en su misma persona... A muchos y graves pecados se expone el que juega ${ }^{13}$.

Tras perder en una partida más de trescientos ducados -cifra desorbitada para la época- el mozo vuelve a casa como un auténtico endemoniado ${ }^{14}$, "más encendido que brasa" (v. 87) y, tras una discusión con sus padres -quienes amablemente le preguntan qué le sucede-, arremete contra ellos, que intentan -en vano- ponerse a resguardo dentro de la casa, viendo los ataques irascibles y furibundos del hijo. Es entonces cuando el padre lo maldice, cargándose la narración de un sentido profético que anuncia lo que sucederá posteriormente:

13 Juan de Zabaleta, El día de fiesta por la mañana y por la tarde, ed. C. Cuevas García, Castalia, Madrid, 1983, pp. 173-174. Aquí nos referimos al cap. 10 de El día de fiesta por la mañana, que trata de "El tahúr". Véase también el cap. 3 de El día de fiesta por la tarde, relacionado con "La casa de juego".

14 Cabe destacar que en todos estos casos horribles y espantosos del Quinientos siempre será el demonio la causa que incita a todos estos personajes a actuar. No se concibe un suceso violento o atroz si no se encuentra ligado a la presencia de un ser diabólico y maligno. Esta omnipresencia de la religión en todas estas obras -a la que nos referiremos más adelante- irá cambiando a medida que avance la historia de esta literatura de cordel. 
Maldito seas tú y el día
en que tú fuiste engendrado,
maldito y descomulgado
sea del sancto Messía,
hijo tan mal doctrinado.
Maldito cuanto comieres
y la tierra que pisares.
Maldito cuanto tomares
y por do quiera que fueres
nunca te falten pesares.
Entre enemigos te veas,
puesto en ásperas montañas,
donde fieras alimañas,
espantables y muy fieras,
te rompan por las entrañas

(vv. 111-125).

Indudablemente estas palabras recuerdan la expulsión del Paraíso -y aquí el padre representa la voz de Dios-, pero sabemos, además, que existen diversos tipos de maldiciones en el Deuteronomio y que también eran de raíz muy popular, ya que, de hecho, se reeditaron más de una vez en pliegos sueltos como las conocidas Maldiciones de Salaya, compuestas por Alonso de Salaya en el siglo Xvi ${ }^{15}$, que Blanca Periñán encuadra dentro de la tradición de los perqués-disparates ${ }^{16}$. Estas imprecaciones pertenecen al folclor tradicional, se remontan a la Antigüedad grecolatina y han desempeñado, desde siempre, un papel muy destacado en las creencias populares de muchas sociedades ${ }^{17}$. Desde el punto de vista gramatical, al igual que las bendiciones, estas maldiciones se construyen con el verbo principal en subjuntivo -tal y como se muestra en el texto-, ya que se trata de un deseo, en este caso negativo y maligno, contra alguien para que, gracias a la invocación y al poder mágico de la palabra, termine cumpliéndose. Así ocurrirá -como veremos más adelante- en esta narración. Si, en el caso de Alonso de Salaya nos hallamos ante un perqué-disparate, ya que las maldiciones de esa obra son "una reacción cómicamente

15 Véanse las entradas 502, 503 y 504 del Nuevo diccionario bibliográfico de pliegos sueltos... de Antonio Rodríguez Moñino.

16 Blanca Periñán, Poeta ludens. Disparate, perqué y chiste en los siglos XVI y XVII, Giardini, Pisa, 1979, p. 33. Véase también Mercedes Fernández Valladares y Víctor Infantes, Pliegos cántabros del siglo XVI (poesía), Cuévano, Santander, 1995.

17 Cf. Miguel G. Aracil, ;Maldito seas!: el libro de las maldiciones, Morales i Torres, Barcelona, 2005; CARlos Nogueira, "Una forma breve olvidada: la praga portuguesa de tradición oral”, RLitPop, 2008, núm. 8, 139-161; y de José MANUEL Pedrosa, Entre la magia y la religión: oraciones, conjuros, ensalmos, Sendoa, Oiartzun, 2000, y "Los padres maldicientes: del Génesis, la Odisea y el Kalevala a la Leyenda de Alfonso X, el Romancero y la tradición moderna”, en La eterna agonía del Romancero, comp. Pedro M. Piñero, Fundación Machado, Sevilla, 2001, pp. 139-177. 
desproporcionada contra el trivial robo de una capa"18, conservamos también del siglo Xvi otra pieza de esta literatura popular donde las imprecaciones y maldiciones están construidas con un fin vindicativo claro $^{19}$, tal y como sucede en esta maldición que inserta Benito Carrasco en su narración.

Tras matar a sus padres con una daga -"la halló toda sangrienta / después quando la sacó” (vv. 134-135)-, parte para Génova, donde se casará con una joven rica, y se dedicará a jugarse la fortuna, ya que "su oficio era boltear / los dados en el tablero" (vv. 146-147). Su suegro intenta que abandone el vicio y para ello lo embarca con otros mercaderes hacia España, pero llegarán a "Berbería", concretamente a Tetuán y allí renegará de su religión ${ }^{20}$ y abrazará la fe musulmana, adoptando el nombre de Almazuil -anteriormente no se había mencionado su nombre en ningún momento. Como ya señalábamos más arriba, hemos conservado un buen número de relaciones de sucesos en pliegos de cordel acerca de historias de cautivos y renegados, sin duda porque se trata de una realidad social bien conocida entonces -otras muchas obras de nuestra literatura son buena muestra de ello. Como apunta Mercedes García-Arenal:

Un phénomène caractéristique de l'histoire méditerranéenne des XVI $\mathrm{I}^{\mathrm{e}}$ XVII ${ }^{\mathrm{e}}$ siècles est celui des "renégats", appelés 'ilj dans les sources arabes. La guerre contre les Ottomans, la course, les galères et les incursions nord-africaines sur les côtes du sud de l'Europe ont entretenu ce phénomène. Entre 1500 et 1750 , des centaines de milliers de chrétiens européens se sont convertis de force ou volontairement à l'islam et sont allés vivre temporairement ou définitivement en terre maghrébine ${ }^{21}$.

El relato que narra Benito Carrasco comienza a agilizarse y en pocos versos nos dice cómo le casaron "con una gallarda mora" (v. 249) -incurriendo así en el pecado de bigamia- y cómo consigue vender como esclavos a los mercaderes que iban con él. El episodio que intercala aquí el autor no sólo dota de mayor verosimilitud toda

18 Blanca Periñán, op. cit., p. 33.

19 Eva B. Carro y María Sánchez Pérez, Literatura popular impresa en La Rioja en el siglo XVI, CiLengua, San Millán de la Cogolla, 2008, pp. 132-156 y 202-210.

20 Parece que la conversión resultaba sencilla y era bastante simple, pues bastaba con pronunciar las palabras la ilaha illà Allah Mohammed rezùl Allah (No hay más dios que Dios y Mahoma es su mensajero), levantando hacia el cielo el dedo índice de la mano derecha. Posteriormente vendría el cambio de vestimenta, la cabeza rasurada y la circuncisión. Véase BARTOLOMÉ BennAssar, ¿Conversos o renegados? Modalidades de una adhesión ambigua de los cristianos al Islam (siglos XVI y XVII), Biblos, Buenos Aires, 1990.

21 Mercedes García-Arenal (dir.), Conversions islamiques. Identités religieuses en Islam Méditerranéen, Maisonneuve et Larose, Paris, 2001, p. 13. Véase también Pedro García Martín, Renegados, viajeros y tránsfugas: comportamientos heterodoxos y de frontera en el siglo XVI, Fugaz, Madrid, 2000. 
su composición, sino que ahonda claramente en las creencias que tanto el Estado como la Iglesia intentaban canalizar por todos los medios durante la época. El insulto hacia los moros se hace patente a lo largo de toda la composición. Como sucede en gran número de estas relaciones de sucesos el miedo y el rechazo hacia los musulmanes -la "perversa seta" (v. 257)- hace que, en muchas ocasiones, se les animalice para ofenderles y atacarles; de ahí términos como "perro" (v. 247), "crudo can" (v. 264), "perro endemoniado" (v. 312), etc. ${ }^{22}$. Al mismo tiempo, el autor aprovecha para explicar en su narración todas las bondades que el pecador ha perdido al renegar de su religión primera:

$$
\begin{aligned}
& \text { mira falso que has trocado } \\
& \text { descanso por el tormento } \\
& \text { y alto por baxo estado. } \\
& \text { Trocaste gloria segura } \\
& \text { por fiera calamidad; } \\
& \text { por el amarga, dulçura; } \\
& \text { claror, por obscuridad; } \\
& \text { por triste hambre, hartura } \\
& \text { (vv. 318-325). }
\end{aligned}
$$

El clima de religiosidad en el que se publica esta obra explica buena parte de las claves que se dan cita a lo largo de la narración. Todo el mensaje moral que se pretende inculcar a través del texto es acorde con la mentalidad surgida tras el Concilio de Trento, de ahí la reprobación de los pecados y los vicios del protagonista. Con la llegada de las ideas contrarreformistas se hace mayor hincapié en que el buen cristiano debe observar un elevado número de preceptos si desea salvarse y gozar del más allá. El miedo ${ }^{23}$ a la condenación eterna y a padecer los rigores del infierno se aúna con otros miedos más mundanos como eran las pestes que asolaban los pueblos en algunos períodos, las frecuentes batallas y guerras durante la época, los desastres naturales que ocasionaban graves pérdidas humanas y económicas, etc. A todo ello hay que unir las numerosas batallas que habían tenido lugar en el Mediterráneo contra los turcos, que alimentaban aún más esa omnipresencia de la religiosidad en todos los aspectos de la vida. En la época en la que se publica este pliego suelto, el imperio turco -y, por lo tanto, los musulmanes- eran vistos

22 Véase Augustin Redondo, "El mundo turco a través de las relaciones de sucesos de finales del s. XVI y de las primeras décadas del s. XVII: la percepción de la alteridad y su puesta en obra narrativa", en Encuentro de civilizaciones (1500-1750). Informar, narrar, celebrar, ed. Antonia Paba, Universidad de Alcalá-Università di Cagliari, Alcalá de Henares, 2003, pp. 235-253.

23 En relación con todos estos aspectos, véase Jean Delumeau, El miedo en Occidente, Taurus, Madrid, 2002. 
como los enemigos por antonomasia de los reinos cristianos de Europa. Se alimenta así el miedo hacia el Otro, ya fueran berberiscos, turcos o moriscos. La creencia en una alianza entre todos ellos para derrocar a la considerada como verdadera fe, la católica, hizo crecer un sentimiento anti-musulmán en todos los estados de la sociedad. Además, las jerarquías civil y eclesiástica alentaban a los españoles a una auténtica cruzada contra los infieles. Como apuntó Augustin Redondo, existen relaciones de sucesos de la época,

que insisten sobre la maldad intrínseca del Otro moro, a quien hay que dominar y aniquilar, en una atmósfera de cruzada rediviva, la que corresponde al imperante espíritu de la Contrarreforma y ha de conducir a la expulsión de $1609^{24}$.

Siguiendo con la trama de nuestro pliego, Almazuil, el renegado, decide comprar a uno de los mercaderes que iba con él hacia España, precisamente a aquél que le había ganado en una partida buena parte de sus dineros. El renegado entonces comienza a martirizar al mercader:

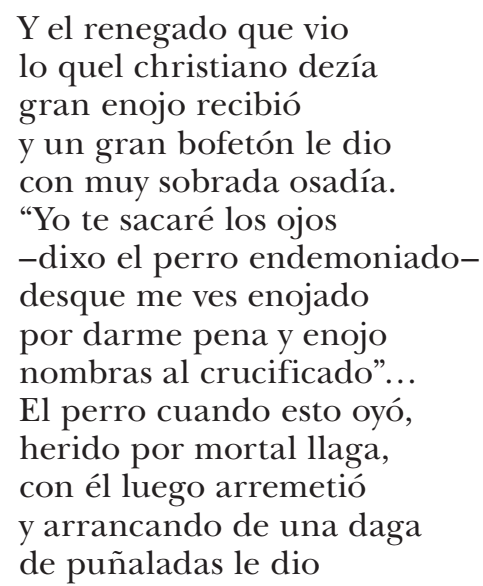

(vv. 306-345).

Benito Carrasco, con una clara intención literaria, abandona el verso octosilábico e incluye dos octavas reales en el momento de mayor tensión narrativa: cuando el mercader invoca a Dios, pidiendo auxilio divino antes de expirar ${ }^{25}$ :

24 Augustin Redondo, "Moros y moriscos en la literatura española de los años 1550-1580", en Judeoconversos y moriscos en la literatura del Siglo de Oro. Las dos grandes minorías étnico-religiosas en la literatura española del Siglo de Oro, Diffusion Les Belles Lettres, Paris, 1995, p. 71.

${ }^{25}$ No es la primera vez que en esta literatura popular impresa los autores, conscientes de su capacidad literaria -ya sea ésta mayor o menor-, deciden adoptar 
"Dulcíssimo Iesús, ya es allegada

la dulce hora de mí más pretendida, quando ha de ser mi alma desatada del ñudo con que el cuerpo la trae asida.

$¡ O$, hora dichosa y bien afortunada, ven muerte, pues serás bien recebida, que morir por mi Christo quiero aora, que un bel morir toda la vida honora!

Dulce Iesús, Señor del alma mía, recibe esta alma allá en tu eterno seno. Y a vos, sacra christífera María, oloroso ciprés en valle ameno, sed intercessora vos, señora pía, pues tengo este tormento por muy bueno. Ya mi dichosa suerte se mejora que un bel morir toda la vida honora"

(vv. 351-366).

Tras el macabro asesinato continúa el tremendismo, ya que empieza de nuevo a blasfemar - "las blasphemas que habló / callo por ser indicentes" (vv. 372-373) - y, luego de esto, comienzan a bajar del monte ciertos monstruos y dragones que, convertidos en serpientes, perros, leones, etc., acabarán devorando al renegado:

\author{
Luego del monte baxaron \\ en figuras de dragones \\ ciertos monstruos y llegaron, \\ y unos perros se tornaron, \\ otros sierpes y leones, \\ otros cuervos se hazían, \\ otros ossos se tornavan \\ y con él arremetían, \\ y con rigor le llagavan \\ y con rabia le mordían. \\ Y allí le despedaçaron \\ donde el perro blasphemó...
}

(vv. 387-398).

\footnotetext{
una métrica u otra dependiendo del sentido que quieran dotar a su narración, como ocurre, por ejemplo en una obra de Juan de Mesa, otro coplero popular del siglo XvI (véase Eva B. CARro y María SÁnchez Pérez, Literatura popular impresa..., especialmente, pp. 120-124). Para un estudio de las dos octavas reales que se incluyen en la obra de Benito Carrasco que ahora analizamos, consúltese María Sánchez Pérez, "La poética de las relaciones de sucesos tremendistas en pliegos sueltos poéticos (siglo XVI): construcción y reelaboración”, Etiópicas. Revista de Letras Renacentistas, 4 (2008), 1-20, en especial, pp. 4-10. En la siguiente dirección en línea (consultada el 24 de marzo de 2010: http:// www.uhu.es /programa_calidad_literatura_amatoria/ etiopicas.htm).
} 
No es infrecuente encontrar en otros casos horribles y espantosos a seres y demonios metamorfoseados en distintos animales o figuras semifantásticas. Ya desde la Edad Media habían existido fábulas morales y terribles, bestiarios de diversos tipos, etc., que se habían asentado en el imaginario y habían ayudado a fijar en la mentalidad de las gentes a toda una serie de animales, bestias y seres monstruosos a los que se les asignaba un determinado valor y una lección morali$z^{2}{ }^{26}$. Con el Concilio de Trento todos estos seres fueron revaluados y también "resignificados" debido a las diferentes amenazas que se cernían sobre la sociedad en aquellos tiempos: musulmanes, herejes, luteranos, etc. Durante los Siglos de Oro "la existencia de los ataques viperinos o de estas mixturas zoomórficas simplemente se justifica en tanto una reproducción microcósmica, la parte visible de la lucha del bien y el mal, que tiene lugar en el plan de la Providencia"27. No es extraño, por tanto, que los autores de los casos horribles y espantosos utilicen a todos estos seres -encarnaciones absolutas del Mal- como castigos enviados por Dios para afligir a la humanidad, extrayendo al mismo tiempo un mensaje didáctico-moral de todo ello.

Como no podía ser de otro modo, termina de forma espeluznante y atroz la vida de este renegado; sin embargo, no finaliza aquí lo truculento del caso, ya que simplemente el hedor que desprendía el cuerpo del asesino acababa con la vida de cuantos encontraba a su paso:

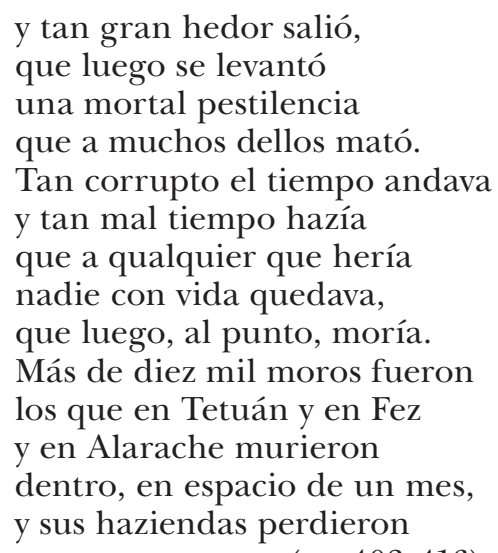

De sobra conocida en la época era la creencia en el diferente olor que desprendían los cuerpos dependiendo de las virtudes o los vicios que hubieran mantenido en vida. Frente al olor a corrupción y putrefacción

${ }^{26}$ Recuérdese, por ejemplo, el caso de los dos lebreles que aparecen en una relación de sucesos de Mateo de Brizuela, en Pedro M. Cátedra, Invención, difusión y..., esp. pp. 219-244.

27 Filippo Picinelli, El mundo simbólico. Serpientes y animales venenosos. Los insectos, Conacyt-El Colegio de Michoacán, México, 1999, p. 16. 
que es característico de herejes, luteranos y otros enemigos de la fe católica, se encontraba el olor suave y delicioso que exhalaban los buenos cristianos -especialmente los que morían con fama de santidad ${ }^{28}$.

Termina Benito Carrasco su composición presentando las mismas características que encontramos en otros finales de estos casos horribles y espantosos; de este modo, en los quince últimos versos de esta obra, el autor nos recuerda que el suceso ha sido cierto y verdadero:

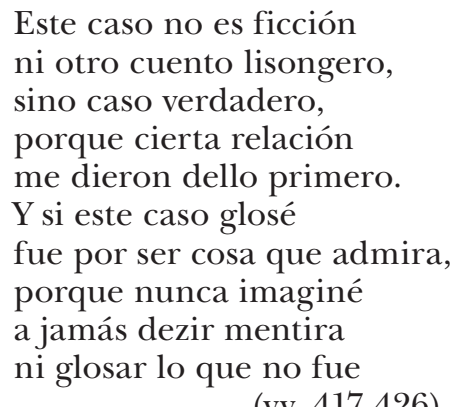

La narración del caso se justifica como un exemplum para "admirar" a sus posibles oyentes y lectores, pero también para alentar a los cristianos en la lucha contra los infieles, denigrando a herejes, enemigos de la fe católica y, sobre todo, renegados. El hecho de que se señale explícitamente que se trata de una noticia nueva y un caso verdadero es algo frecuente en toda esta literatura popular impresa. Como señaló Pedro M. Cátedra:

El interés por la nueva, la noticia, es, en principio, una marca de los tiempos, pero acabará convirtiéndose en una estrategia, en un marco o contexto narrativo, si se quiere, que justifica otro interés más profundo por los casos admirables y espantosos en sí. No niego que, en la recepción, se dé una contextualización a varios niveles, desde el individual, hasta el social, y que la novedad sea, en efecto, un principio canalizador del interés, pero el aspecto escatológico de la noticia es el que se enraíza y acaba enraizando mentalidades ${ }^{29}$.

Ese interés por la noticia provocó una auténtica fiebre informativa que afectó no solamente a la Península ibérica, sino a todos los países de la Europa del Quinientos. Es más, fueron numerosos los impresores que se instalaron en el Nuevo Mundo después de la conquista española, si bien es cierto que en los primeros tiempos predominaron las obras de didáctica y moral religiosa, bajo el férreo y severo

28 No solamente el olor diferenciaba a los muertos, los cadáveres también presentaban distintos signos y marcas, de ahí que frente a los cuerpos negros, cárdenos y denegridos de los herejes, endemoniados, etc., se hallan los cuerpos tersos e incorruptos de los que mueren en olor de santidad.

29 Pedro M. Cátedra, Invención, difusión y..., pp. 109-110. 
control que adoptaron las diferentes congregaciones de franciscanos, dominicos, etc. instaladas en los territorios americanos ${ }^{30}$.

Para finalizar, Benito Carrasco en la última estrofa dirige su atención hacia el auditorio para que las gentes enmienden sus vidas y cumplan con los preceptos divinos:

\begin{abstract}
Sirvamos a Dios eterno como somos obligados, para que del crudo infierno podamos ser libertados para el siglo sempiterno
\end{abstract} (vv. 427-431).

La narración que se nos presenta en este pliego suelto de finales del siglo Xvi representa lo que, desde la mentalidad de la época, suponía la escalada del crimen: partiendo de un pequeño vicio privado, que es el juego, el protagonista cae en el pecado -blasfemar-y, de este modo, comienza perdiendo el respeto a sus padres -lo que sería atentar contra el cuarto mandamiento de la Ley de Dios- y, posteriormente, los asesina -incumpliendo así el quinto mandamiento. Una vez cometido el parricidio, la escala de pecados y crímenes se suceden ininterrumpidamente, ya que es pecado jugarse la dote de la mujer, pero también es un crimen ser bígamo y renegar de la propia fe -piénsese que la Inquisición condenaba delitos como la herejía y la apostasía, pero también la bigamia. Por último, el renegado acaba persiguiendo y martirizando a los cristianos, personificados en el mercader, lo cual supone ya un crimen espantoso. Ahora bien, como no podía ser de otra manera en esta literatura popular impresa, el criminal recibe el justo castigo: es torturado, muere y, además, apesta, señal inequívoca de su condenación eterna. Benito Carrasco, de este modo, decide entregar a la imprenta un texto con una clara finalidad didáctico-moral -recordemos que en el título se señalaba que era una obra que contenía "cosas de grande admiración y exemplo para que los padres castiguen a sus hijos"- para publicar y difundir un caso horrible y espantoso acorde con la mentalidad del siglo Xvi en el que se reprueban los vicios en los que pueden caer los mortales y, cómo a partir de ese momento, pueden sucederse toda una serie de pecados y crímenes que llevarán a la condenación de los hombres, de acuerdo, por lo tanto, con la mentalidad de finales del Quinientos.

María Sánchez Pérez

Consejo Superior de Investigaciones Científicas, Madrid

30 Como acercamiento y estudios de conjunto pueden verse Stella Maris Fernández, La imprenta en Hispanoamérica, Asociación Nacional de Bibliotecarios, Archiveros y Arqueólogos, Madrid, 1977; José Torre Revello, El libro, la imprenta y el periodismo en América durante la dominación española, UNAM, México, 1991, y JACQUES Lafaye, Albores de la imprenta: el libro en España y Portugal y sus posesiones de ultramar (siglos XV-XVI), F.C.E., México, 2002. 


\section{ANEXO}

\section{DESCRIPCIÓN TIPOBIBLIOGRÁFICA}

Caso admirable y espantoso agora nue- | uamente sucedido en este año de mil y quinientos | y ochenta y siete, que trata como vn mal hijo fue desobediente a sus pa- | dres, y de la maldicion que su madre le hecho, y como se torno Moro. | y el riguroso castigo que Dios hizo sobre el. Co otras cosas de gran- $\mid$ de admiracion y exemplo para que los padres castiguen a | sus hijos. Compuestos por Benito Carrasco, | natural de Fuente Vejuna. | Impressa con Licencia en casa de Hubert Gotard. | Año de M. D. Lxxxviij.

[A1r-A4v] MVeua mi lengua el Se or / Iesus viuo omnipotente

Al final, en A4v: Vendense en casa de Pedro Ferrer | librero.

4. 4 hojas, letra redonda, a dos columnas.

S. 1. [Barcelona], Hubert Gotard, 1588

RM 94.5

\section{Edición}

${ }^{[\mathrm{A} 1 \mathrm{r}]}$ Caso admirable y espantoso, agora nuevamente sucedido en este año de mil y quinientos y ochenta y siete, que trata cómo un mal hijo fue desobediente a sus padres y de la maldición que su madre le hechó, y cómo se tornó moro. Y el riguroso castigo que Dios hizo sobre él, con otras cosas de grande admiración y exemplo para que los padres castiguen a sus hijos. Compuesto por Benito Carrasco, natural de Fuente Vejuna. Impressa con licencia en casa de Hubert Gotard. Año de M.D.L.xxxviij.

Mueva mi lengua el Señor Iesús, vivo omnipotente, para que con su favor un caso admirable cuente,

5 de gran exemplo y primor. Tené atentos los oídos, gente por Dios redemida, y oyan los que son nacidos una nueva y no fingida

10 de dos casos sucedidos.

Christiana congregación, oíd, por Dios verdadero, que este cuento no es ficción, sino caso verdadero

15 muy digno de admiración. Començad, pluma veloz, a narrar lo succedido, pues que cierto ha acontecido este caso cruel, atroz,

20 según por nueva he sabido. 
COMIENZA LA OBRA

Allá dentro, en Lombardía, sucedió este cuento estraño en la ciudad de Cambría, el qual es de tanto engaño, que tiembla la lengua mía. En la ciudad que he contado un noble varón vivía, rico y bien aparentado y un solo hijo tenía, muy querido y regalado.

Este niño se crió de contino en gran regalo, y en maldad se exercitó y al cabo, salió tan malo que en mal estado acabó. Su vicio era blasphemar de Iesuchristo sagrado y occupávase en jugar, ${ }^{[\mathrm{Alv}]}$ y el padre era muy pagado sin quererle castigar.

Y estando jugando un día, perdió trecientos ducados, y con sobrada osadía blasphemava y escupía

45 de los sanctos consagrados. Y uno le reprehendió las blasphemias que dezía, y el perverso respondió: «Maldita sea la hora y día que mi madre me parió.

»Y si a mi padre topara, juro, por el alto cielo, los cabellos le messara 55 las sembrara por el suelo». Y luego en su casa entró, como un león sanguinoso, el padre quando le vio, con rostro afable y amoroso,

60 desta suerte preguntó:

«Ven acá, ¿dónde has estado, que no has venido a comer y vienes muy enojado?» Dixo el falso, malmirado:

$65 \ll$ En casa de Lucifer, he hos de dar esse disqüento, puto viejo endemoniado.

Voto a tal que estoy espantado 
en ver quánto sufrimiento

Dixo el padre con temor, viéndole tan enojado: «Hijo mío, tan amado, ¿assí pagas el amor con que siempre t'é criado?» Respondió con gran corage y un semblante fiero, airado: «Por Iesuchristo sagrado a vos y a vuestro linaje os venda por un cornado».

La madre le salió a ver y dixo: «Desvergonçado, vellaco, ¿y tú eres osado a tu padre responder?

85 dime, essento malmirado». El hijo quando lo oyó, más encendido que brasa con la madre arremetió, y arrastrándola por la casa los cabellos le arrancó.

Viendo el padre el mal intento del hijo falso y cruel, huyó luego en el momento y el hijo corrió tras él,

95 hasta entrar en su aposento. Y las puertas atrancó el padre atemorizado y el mal hijo quando vio el aposento cerrado

100 a grandes vozes llamó,

diziendo: «Abrid, viejo loco, que no os aprovecha nada ${ }^{[\mathrm{A} 2 \mathrm{r}]}$ tener la puerta cerrada, ni aunque deis vozes tampoco

105 con la vieja endemoniada». Dixo el padre: «Gran Señor, Iesús, summo Redemptor, Rey de abismo, mar y suelo, justicia venga del cielo

110 contra este falso traidor.

»Maldito seas tú y el día en que tú fuiste engendrado, maldito y descomulgado sea del sancto Messía,

115 hijo tan mal doctrinado. Maldito quanto comieres y la tierra que pisares. 
Maldito quanto tomares y por do quiera que fueres,

120 nunca te falten pesares.

»Entre enemigos te veas, puesto en ásperas montañas, donde fieras alimañas, espantables y muy fieras,

125 te rompan por las entrañas». Y todo esto suplicó a Iesús, gran Rey del cielo, y en la tierra se postró tres vezes besando el suelo

130 contra el hijo que engendró.

Y una daga que hincó en la puerta, tened cuenta, el moço quando llegó la halló toda sangrienta

135 después quando la sacó. Y no paró en la ciudad, que la justicia temía, pero con gran brevedad para Génova partía,

140 metido en gran ceguedad.

Desque a Génova llegó muchos que lo conocieron desposalle pretendieron, y luego se desposó

145 y gran hazienda le dieron. Su oficio era boltear los dados en el tablero, y tal maña se fue dar, qu'en poco vino a jugar

150 la más parte del dinero.

Viendo la gran perdición el suegro, varón prudente, le riñó muy reziamente, también un noble varón

155 que allí se halló presente: «Muy mal camino lleváis -le dixo el suegro enojadoy, assí, estoy determinado hijo, que luego os partáis

160 con un mercader honrado,

»el qual parte para España con muy gran mercaduría. Yo, hijo, mucho querría dar orden, manera o maña, ${ }^{[\mathrm{A} 2 \mathrm{v}]}$

165 que vais en su compañía. Yo os daré seis mil ducados 
que llevéis para emplear* y apartaos de esse jugar que al fin, los hombres honrados

170 han de saber grangear».

Y él dixo: «Yo soy contento, señor, de lo obedecer». Y el suegro, luego al momento, fue hablar al mercader

175 y le contó todo el cuento. Y él dixo que le plazía de muy sana voluntad, pero que con brevedad aderecen que otro día

180 se parten de la ciudad.

Y el suegro muy plazentero le dio los seis mil ducados en alhajas y dinero, y assí fueron embarcados

185 y otro honrado passajero. Después que embarcados fueron, metidos en alta mar, assentáronse a jugar y el dinero le cogieron

190 que su suegro le fue a dar.

Pero como Lucifer en él estava encerrado, dos mil vezes ha intentado de matar al mercader

195 quel dinero le ha ganado. Pero como prosiguieron su viaje todavía, una isleta descubrieron por lo qual alegres fueron

200 porque agua dulce tenía.

Y desque cerca llegaron, con entrañable desseo, todos se desembarcaron, por tomar algún recreo

205 a la isleta caminaron. El que el dinero perdió, que era el hijo inobediente, que a su madre maltrató, en la nave se quedó

210 fingiendo quedar doliente.

Y assí se quedó con él poca gente y desarmada, el qual, con ira cruel, echó mano de su espada

215 y a una rodela o broquel, 
diziendo: «Alçad luego al punto,

las velas y de do diere,

y el que assí no lo hiziere

muerto quedará o difunto

220 si contra mi intento fuere».

Todos con el gran temor que tuvieron, al momento dieron velas al rigor del mar y con fresco viento

225 se fueron con el traidor. Y con la nave se alçó ${ }^{[A 3 r]}$ y con la mercaduría, y la otra gente quedó

230 en la isla y se partió.

La nave mandó guiar la buelta de Berbería, y a Tetuán fue aportar y allí vino a renegar

235 de Dios y sancta María. Muchos moros acudieron viendo la nave surgida, $\mathrm{y}$ al punto como supieron a qué era su venida

240 muy gran honra le hizieron.

Y luego allí le informaron en aquella mala seta, y allí todos blasphemaron de la fe sancta y perfecta

245 primera, que le mudaron. Almazuil le llamaron al perro, y luego a la hora gran dinero le allegaron, con una gallarda mora

250 al momento le casaron.

La otra gente quedó en la isla o despoblado, muy grande hambre passó qu'en cinco días no comió

255 ninguno dellos bocado. Mas tres galeras llegaron de aquella perversa seta y mucho espanto tomaron viendo gente en la isleta,

260 y captiva la llevaron.

Llévanlos a Tetuán a venderlos al mercado, donde estava el renegado Almazuil, crudo can, 
265 con la mora desposado. $\mathrm{Y}$ el dañado desque vio venderse aquel mercader al momento lo compró, y el precio que por él dio

270 fue gran parte de su haver.

Y a su casa le llevó bien rodeado de penas y muy rezio le açotó amarrado a unas cadenas,

275 donde su saña mostró, diziendo: «Aquí pagarás los restos que me tiraste, y a mis manos morirás y no bolverás jamás

280 donde los hijos dexaste».

Y con gran dolor dezía el mercader lastimado: «A ti, mi Christo sagrado, encomiendo el alma mía,

285 límpiala Tú de peccado. Alto Señor que con motes fuiste escupido de ingratos, y el que en casa de Pilatos ${ }^{[\mathrm{A} 3 \mathrm{v}]}$ llevó cinco mil açotes,

290 padeciendo malos ratos.

»Hijo de la Virgen pura, sagrada, divina planta, fuiste con angustia tanta por las calles de amargura

295 con la soga a la garganta. Señor, que para dar luz al hombre por ti criado fuiste mi Dios despojado y enclavado en una cruz

300 y abierto por el costado.

"Y pues Tú fuiste por mí desnudo y avergonçado, yo huelgo ser açotado, y passar esto por ti

305 muy poco es lo que he passado». $\mathrm{Y}$ el renegado que vio lo quel christiano dezía gran enojo recibió y un gran bofetón le dio

310 con muy sobrada osadía.

«Yo te sacaré los ojos -dixo el perro endemoniadodesque me ves enojado 
por darme pena y enojo

315 nombras al crucificado».

Dixo el christiano sediento:

«No conoces tu peccado, mira falso que has trocado descanso por el tormento,

320 y alto por baxo estado.

»Trocaste gloria segura por fiera calamidad; por el amarga, dulçura; claror, por obscuridad;

325 por triste hambre, hartura. Diote Dios libre alvedrío para que le conociesses y su sancta ley siguiesses, y para que des desvío

330 al demonio y dél huyesses.

"La sancta Iglesia Romana te hizo bien fortunado, tú, falso, lo has trocado dexando muger christiana

335 y con mora te has casado. Mira quel falso demonio te trae ciego, engañado, porque agora has profanado el divino matrimonio

340 y dos vezes te has casado».

El perro, quando esto oyó, herido por mortal llaga con él luego arremetió, y arrancando de una daga

345 de puñaladas le dio. Desque se sintió herir sus ojos tornados fuentes queriendo al cielo partir. Aquestos versos siguientes

350 començó luego a dezir: ${ }^{[A 4 r]}$

«Dulcíssimo Iesús, ya es allegada la dulce hora de mí más pretendida, quando ha de ser mi alma desatada del ñudo con que el cuerpo la trae asida.

355 O, hora dichosa y bien afortunada, ven muerte, pues serás bien recebida, que morir por mi Christo quiero aora, que un bel morir toda la vida honora!

»Dulce Iesús, Señor del alma mía,

360 recibe esta alma allá en tu eterno seno. Y a vos, sacra christífera María, oloroso ciprés en valle ameno, 
sed intercessora vos, señora pía,

pues tengo este tormento por muy bueno.

365 Ya mi dichosa suerte se mejora

que un bel morir toda la vida honora».

Acabando de hablar

estos versos que he contado, en el punto fue a espirar,

370 y el perverso renegado

luego empeçó a blasphefar.

Las blasphemas que habló

callo por ser indicentes,

porque la tierra mordió

375 y cruxía con los dientes, pero después lo pagó.

Los ganados que allí avía conocían su malicia, pidiendo al sacro Messía

380 contra aquel traidor justicia bramando con osadía.

El buen mercader dichoso murió allí martirizado, quedó su cuerpo esmaltado

385 de un claror maravilloso y de olores rodeado.

Luego de un monte baxaron en figura de dragones ciertos monstruos y llegaron,

390 y unos perros se tornaron, otros sierpes y leone, otros cuervos se hazían, otros ossos se tornavan y con él arremetían,

395 y con rigor le llagavan y con rabia le mordían.

Y allí le despedaçaron donde el perro blasphemó, y a la sierra se tornaron

400 donde primero baxaron, y el cuerpo allí se quedó. En su casa o pertinencia y tan gran hedor salió, que luego se levantó

405 una mortal pestilencia que a muchos dellos mató.

Tan corrupto el viento andava y tan mal tiempo hazía que a qualquier que hería

410 nadie con vida quedava, que luego al punto moría. ${ }^{[\mathrm{A} 4 \mathrm{v}]}$ 
Más de diez mil moros fueron

los que en Tetuán y en Fez

y en Alarache murieron

415 dentro, en espacio de un mes, y sus haziendas perdieron.

Este caso no es ficción, ni otro cuento lisongero, sino caso verdadero,

420 porque cierta relación me dieron dello primero.

Y si este caso glosé fue por ser cosa que admira, porque nunca imaginé

425 a jamás dezir mentira, ni glosar lo que no fue.

Sirvamos a Dios eterno como somos obligados, para que del crudo infierno

430 podamos ser libertados para el siglo sempiterno.

\section{Laus Deo}

Véndense en casa de Pedro Ferrer, librero.

\section{Notas textuales}

V. 167: emplear] emplar. 
